\title{
Ectopic Expression of Decorin Protein Core Causes a Generalized Growth Suppression in Neoplastic Cells of Various Histogenetic Origin and Requires Endogenous p21, an Inhibitor of Cyclin-dependent Kinases
}

\author{
Manoranjan Santra, ${ }^{\star}$ David M. Mann, ${ }^{\ddagger}$ Edward W. Mercer, ${ }^{\|}$Thomas Skorski,,$\|$Bruno Calabretta, ${ }^{\|}$and Renato V. Iozzo*\| \\ *Department of Pathology, Anatomy and Cell Biology, Thomas Jefferson University, Philadelphia, Pennsylvania 19107; ${ }^{\ddagger}$ Holland \\ Laboratories, American Red Cross, Rockville, Maryland 20855; ${ }^{\circledR}$ Department of Biochemistry and Molecular Biology and the Institute for \\ Biomedical Sciences, George Washington University Medical Center, Washington, DC 20037; and the "Kimmel Cancer Center, Jefferson \\ Medical College, Thomas Jefferson University, Philadelphia, Pennsylvania 19107
}

\begin{abstract}
Decorin belongs to a family of secreted, small, leucine-rich proteoglycans that affect matrix assembly and cellular growth. Ectopic expression of decorin proteoglycan or protein core as a mutated form lacking any glycosaminoglycan side chains induced growth suppression in neoplastic cells of various histogenetic origins, including tumor cells derived from gastrointestinal, genital, skeletal, cutaneous, or bone marrow tissues. Exogenously added recombinant decorin also suppressed overall growth of the parental cell lines. In all stably-transfected clones, growth retardation was specifically associated with induction of the potent cyclin-dependent kinase inhibitor p21, but not p27, and subsequent translocation of $\mathrm{p} 21$ protein into the nuclei of decorin-expressing cells. This led to a greater proportion of the cells arrested in $G_{1}$ phase of the cell cycle. These changes were independent of functional p53 or retinoblastoma protein. De novo expression of decorin in HCT116 human colon carcinoma cells harboring a disrupted p21 gene failed to induce growth suppression, in contrast to the wild-type cells in which p21 and growth arrest could be induced. These findings indicate that ectopic production of decorin protein core can retard the growth of a variety of tumor cells and that endogenous p21 is a required downstream effector of this biological axis. (J. Clin. Invest. 1997. 100:149-157.) Key words: proteoglycans $\bullet$ stable transfection • cell division • proliferation
\end{abstract}

\section{Introduction}

There is increasing evidence that decorin, a member of the expanding gene family encoding the small leucine-rich proteoglycans (SLRPs), plays an important role in modulating cell adhesion, migration, proliferation, and collagen fibril formation (1). Decorin can bind in vitro to a variety of adhesive and nonad-

Address correspondence to Renato V. Iozzo, M.D., Department of Pathology, Anatomy and Cell Biology, Room 249, Jefferson Alumni Hall, Thomas Jefferson University, 1020 Locust Street, Philadelphia, PA 19107. Phone: 215-503-2208; FAX: 215-923-7969; E-mail: iozzo@ lac.jci.tju.edu.

Received for publication 5 February 1997 and accepted in revised form 7 April 1997.

J. Clin. Invest.

(C) The American Society for Clinical Investigation, Inc.

0021-9738/97/07/0149/09 \$2.00

Volume 100, Number 1, July 1997, 149-157 hesive proteins including fibronectin, thrombospondin, various types of collagens, $\mathrm{C} 1 \mathrm{q}$, and transforming growth factor- $\beta$ $(\mathrm{TGF}-\beta)^{1}(2)$. The binding of decorin to fibrillar collagen carries important biological implications as recently demonstrated by the phenotype of mice lacking the decorin gene (3). In these mutant animals, disruption of the decorin gene leads to skin fragility and abnormal collagen morphology, characterized by uncontrolled lateral fusion of fibrils. Binding of decorin to TGF- $\beta$ prevents the fibrosis of renal glomeruli by neutralizing its biological activity (4). Decorin cDNA was recently used as a novel gene therapy tool for treatment of fibrotic diseases caused by TGF- $\beta$ (5).

Decorin has been implicated in the control of cell proliferation by several key observations. Forced expression of decorin in Chinese hamster ovary cells leads to a decreased growth rate, lower saturation density, and altered morphology (6). It has been suggested that decorin causes these changes in this cell system by sequestering TGF- $\beta$, an autocrine growth stimulator for these cells (7). Decorin is markedly upregulated during quiescence in human diploid fibroblasts $(8,9)$ and its expression is strongly suppressed upon viral transformation with SV40 (8). Decorin is rarely expressed by malignant epithelial cells from a wide variety of human tumors including colon, pancreas, prostate, and breast carcinomas (10). However, in the tumor stroma of colon cancer, the amount of decorin proteoglycan is increased markedly through a process that involves hypomethylation of the decorin gene (11) as well as induction of this gene product via tumor-secreted cytokines (12).

Using a gene transfer approach in human colon carcinoma cells that do not constitutively express this gene, we discovered that the de novo expression of decorin reverted the cells to a normal phenotype: the cells lost anchorage-independent growth, failed to generate tumors in scid/scid mice, and became arrested in the $\mathrm{G}_{1}$ phase of the cell cycle (13). The cells could reenter the cell cycle when decorin expression was abrogated by decorin-specific antisense oligodeoxynucleotide treatment (13). This decorin-induced growth arrest was associated with a marked induction of $\mathrm{p} 21^{\text {WAF1/CIP1 }}(\mathrm{p} 21)$, a potent inhibitor of cyclin-dependent kinases (CDK) (14), thus suggesting that decorin might be a component of a negative loop that controls cell proliferation.

1. Abbreviations used in this paper: $\mathrm{CDK}$, cyclin-dependent kinase; GAPDH, glyceraldehyde-3-phosphate dehydrogenase; p21, the inhibitor of cyclin-dependent kinase activity $21^{\text {WAFI/CIPI; }}$ p27, the inhibitor of cyclin-dependent kinase activity $\mathrm{p} 27^{\text {Kip } 1}$; SDS-PAGE, Na-dodecylsulfate polyacrylamide gel electrophoresis; TGF- $\beta$, transforming growth factor- $\beta$. 
In this report we sought to determine whether: $(a)$ the decorin-induced growth suppression is a general phenomenon, capable of occurring in tumor cell lines with a diverse histogenetic background; $(b)$ these effects are mediated by the protein core itself; $(c)$ concomitant upregulation of p21 is invariably associated with the decorin-induced growth suppression; and $(d)$ the presence of endogenous p21 protein is a necessary requirement for decorin-induced growth suppression. The results showed that ectopic expression of decorin, synthesized either as a proteoglycan or as a protein core, suppressed the growth of all established neoplastic cell lines derived from mineralized bone, uterus, skin, soft tissues, and bone marrow. In addition, exogenously added recombinant decorin also suppressed overall growth of the parental cell lines. All of the decorin-expressing tumor cell lines showed an increase proportion of cells in $\mathrm{G}_{1}$ phase of the cell cycle and a concurrent upregulation of $\mathrm{p} 21 \mathrm{mRNA}$ and protein, but not of $\mathrm{p} 27^{\text {Kip1 }}$ (p27), another CDK inhibitor. Tumor cells with a disrupted p21 gene failed to respond to ectopic decorin expression in contrast to the wild-type cells in which p21 and growth arrest was inducible by decorin. We conclude that decorin is a generalized growth suppressor of neoplastic cells acting from the outside of the cell and that endogenous p21 is a required downstream target gene for this biological axis. The heightened biosynthesis and secretion of decorin by tumor stroma cells may represent a mechanism designed to counteract the invading neoplastic cells.

\section{Methods}

Cell cultures. The following human established and primary cell lines were used: cervical carcinoma (HeLa), SV40-transformed skin fibroblast (LNSV), osteosarcoma (MG-63 and Saos-2), colon carcinoma cells, WiDr/HT-29 and HCT116 with or without a functional p21 gene (15), fibrosarcoma (HT-1080), squamous cell carcinoma (A431), prostate adenocarcinoma (PC-3), melanoma (UACC903), lymphoblastic leukemia (MOLT-4), human promyelocytic leukemia (HL-60), human erythroleukemia (HEL92.1.7), human lymphoblastic leukemia (CCRF-SB), and normal diploid lung (IMR-90) and skin (N19-91) fibroblasts. Cells were obtained from either American Type Culture Collection (Rockville, MD) or from the Kimmel Cancer Center Cell Culture Facility (Philadelphia, PA). Mouse melanoma M2 cells were obtained from Dr. J. Fiddler (MD Anderson Cancer Center, Houston, TX). The cells were maintained in DME supplemented with 5\% FBS, $2 \mathrm{mM}$ glutamine, $100 \mathrm{U} / \mathrm{ml}$ penicillin and $50 \mu \mathrm{g} / \mathrm{ml}$ streptomycin. The hematopoietic cell lines were cultured in RPMI 1640 medium supplemented as above.

Construction of CMV-expression vector and stable transfection. The codon (TCT) of the decorin cDNA encoding the amino acid $\mathrm{Ser}^{7}$ of the mature protein core was mutated into GCT (Ala) (16). The Ser-7 holds the glycosaminoglycan sugar chain in the decorin molecule, and it has been shown previously that this mutagenized decorin is secreted as the core protein with no detectable glycosaminoglycan side chain (16). The mutated decorin cDNA was digested with EcoRI and fused to the $3^{\prime}$ end of the human cytomegalovirus (CMV) early gene promoter/enhancer in a mammalian expression vector pcDNA3 (Invitrogen Corp., San Diego, CA). The orientation of the insert was verified by restriction endonuclease digestion and DNA sequencing. The full-length decorin vector cloned into pcDNA3 is the same as described previously (13) and results in two transcripts of $\sim 1.6$ and $\sim 1.9 \mathrm{~kb}$, respectively. The $\Delta$ decorin contained an addition $200 \mathrm{bp}$ of $3^{\prime}$ untranslated region and thus results in two transcripts of $\sim 1.6$ and $\sim 2.1 \mathrm{~kb}$, respectively (16). The different tumor cell lines were stably transfected by the calcium phosphate procedure (13). Briefly, $\sim 10^{6}$ cells were transfected with $20 \mu \mathrm{g}$ of purified DNA and incubated at $37^{\circ} \mathrm{C}$ in a humidified incubator for $12-16 \mathrm{~h}$. After $48 \mathrm{~h}$ of incubation in nonselective medium to allow expression of the transferred genes to occur, the cells were trypsinized and replated at a 1:10 dilution. Within $12-16 \mathrm{~h}, \mathrm{G} 418(800 \mu \mathrm{g} / \mathrm{ml})$ was added to the medium with fresh addition of the drug every $4-5 \mathrm{~d}$. Colonies were first detected after $14 \mathrm{~d}$ in the selective medium and 7-14 $\mathrm{d}$ later, independent colonies were trypsinized in cloning cylinders and transferred to microtiter wells. In the case of HL-60, the transfected cells were diluted with the RPMI medium containing $800 \mu \mathrm{g} / \mathrm{ml} \mathrm{G418}$ and replated in 96well plates in such a way that each well contained a single cell. After $\sim 30$-d exposure to $800 \mu \mathrm{g} / \mathrm{ml} \mathrm{G} 418$, the cells were cultured routinely with G418 $(300 \mu \mathrm{g} / \mathrm{ml})$.

Northern and Western blot analyses, and cell proliferation assays. Total RNA was extracted from the different cells using the TRIReagent $^{\mathrm{TM}}$ (Molecular Research Center, Inc., Cincinnati, OH). Total RNA (20 $\mu \mathrm{g}$ per lane) was electrophoresed in formaldehyde/1\% agarose gel, transferred to nitrocellulose membranes (Schleicher \& Schuell, Inc., Keene, $\mathrm{NH}$ ), and hybridized with ${ }^{32} \mathrm{P}$-multiprime-labeled (Stratagene, Inc., LaJolla, CA) decorin cDNA (17) or p21 WAFI/CIP1 cDNA (18). Quantity of RNA was normalized on glyceraldehyde-3-phosphate dehydrogenase (GAPDH) mRNA level (19). For immunoblotting, media conditioned by the various cells for $24 \mathrm{~h}$ in $0.1 \%$ serum was precipitated with $5 \mathrm{vol}$ of ethanol containing $1.3 \%(\mathrm{wt} / \mathrm{vol})$ potassium acetate at $-20^{\circ} \mathrm{C}$ overnight and centrifuged at $10,000 \mathrm{~g}$ for $5 \mathrm{~min}$. Pellets were dried and dissolved in SDS sample buffer, separated in $7.5 \%$ Na-dodecylsulfate polyacrylamide gel electrophoresis (SDSPAGE), transferred onto nitrocellulose membranes, and blocked with $5 \%$ dried milk for $18 \mathrm{~h}$. Immunodetection was performed using rabbit polyclonal antipeptide antibodies to decorin (17), mouse monoclonal 6B6 antibodies directed toward p21 or rabbit polyclonal against p27 protein (PharMingen, San Diego, CA). After $3 \mathrm{~h}$, the filters were rinsed several times with PBS and incubated with 1:5,000 dilution of horseradish peroxidase-conjugated anti-rabbit antibodies for $2 \mathrm{~h}$. Bound protein was detected with the enhanced chemiluminescence kit (Amersham Corp., Arlington Heights, IL). The CellTiter $96^{\mathrm{TM}}$ Aqueous Non-Radioactive Cell Proliferation Assay (Promega Corp., Madison, WI) was used to determine the number of viable cells in a proliferative phase (13).

Purification of recombinant human decorin. Human recombinant decorin was purified from media conditioned by Chinese hamster ovary cells stably transfected with a decorin expressing vector as described before with modifications (6). Approximately 5-10 liters of pooled serum-free conditioned medium was brought to $300 \mathrm{mM} \mathrm{NaCl}$ before passing over an 80-ml DEAE-Sepharose column containing a 30-ml Sepharose-4B precolumn guard to remove nonspecific Sepharose-binding molecules. After washing the DEAE column exhaustively with $300 \mathrm{mM} \mathrm{NaCl}$ in phosphate buffer, $\mathrm{pH}$ 7.4, the column was washed with $6 \mathrm{M}$ urea/ $6 \mathrm{mM} \mathrm{CHAPS} / 300 \mathrm{mM} \mathrm{NaCl}$, followed by a 1-liter wash in $300 \mathrm{mM} \mathrm{NaCl}$ to remove urea/CHAPS, and bound proteins were eluted with a $0.3-1 \mathrm{M}$ gradient of $\mathrm{NaCl}$. Fractions containing decorin, identified by SDS-PAGE, were pooled and diluted with an equal volume of saturated ammonium sulfate in 50 $\mathrm{mM}$ phosphate buffer, $\mathrm{pH} 6.3$, and bound to a $\mathrm{C} 4$ hydrophobic interaction column (Hydrocell C4-1000; BioChrom Labs Inc., Terre Haute, Indiana). Bound material was eluted with a simultaneous reverse salt gradient $(2.5-0 \mathrm{M})$ of ammonium sulfate in $50 \mathrm{mM}$ phosphate buffer, $\mathrm{pH} 6.3$, and of ethylene glycol (0-50\%) in $50 \mathrm{mM}$ phosphate buffer, $\mathrm{pH}$ 8.3. We used TOSOH HPLC system (TSK 6011I) equipped with a TSK 6041 UV detector and a GM8010 gradient monitor. Elution profiles were monitored at A $280 \mathrm{~nm}$ and samples from the major peaks were examined by SDS-PAGE before pooling fractions containing decorin. Ethylene glycol was removed from pooled decorin eluted from the C4 column by dialysis against PBS, using 30 $\mathrm{kD}$ MW cut off, and finally concentrated by repeating DEAE chromatography. The final product was checked for purity by SDS-PAGE and immunoblotting with a polyclonal antibody specific for the decorin protein core (17). Because of the nondenaturing conditions and the lack of chaotropic agents during the purification steps, all the pu- 
rified recombinant decorin was essentially native, similar to that synthesized endogenously by the stably transfected cells (see above). To test for biological activity, we used the parental cell lines and cultured them in the absence or presence of decorin $(100 \mu \mathrm{g} / \mathrm{ml} ; \sim 1 \mu \mathrm{M})$ for 24 and $48 \mathrm{~h}$, respectively. At the end of the incubation, we measured the cell number by the nonradioactive colorimetric assay described above.

FACS ${ }^{\circledR}$ analysis and immunohistochemistry. The cells were stained with propidium iodide $(2 \mathrm{mg} / \mathrm{ml})$ in $4 \mathrm{mM} \mathrm{Na}$ citrate buffer containing 3\% Triton X-100 and RNase A $(100 \mu \mathrm{g} / \mathrm{ml})$. The stained cells were analyzed by FACS ${ }^{\circledR}$ as described before (13). For immunohistochemistry, cells were fixed for $8 \mathrm{~min}$ in $4 \%$ paraformaldehyde, permeabilized for $2 \mathrm{~min}$ in $0.2 \%$ Triton X-100, and stained with the $6 \mathrm{~B} 6$ mouse anti-human p21 monoclonal antibody $(5 \mu \mathrm{g} / \mathrm{ml}$, PharMingen $)$ and a fluorescein-conjugated donkey anti-mouse IgG (Jackson ImmunoResearch Labs, Inc., West Grove, PA; 1:30). The cells were examined using a confocal microscope with a Bio-Rad MRC-600 system interfaced to a Olympus IMT-2 inverted microscope using an aircooled argon laser for excitation.

\section{Results}

Lack of constitutive decorin expression in established cancer cell lines and SV40-transformed cells. In spite of the fact that decorin is expressed by a wide variety of adult and embryonic mammalian tissues (2), a survey of several transformed cell lines revealed that only the osteosarcoma MG-63 cells expressed decorin mRNA (Fig. $1 A$, lane 8 ), in addition to lung and skin fibroblasts (Fig. $1 A$, lanes 4 and 9 , respectively). A protracted exposure revealed very low levels of decorin mRNA in the melanoma cell line UACC-903. When normalized on the housekeeping gene GAPDH, however, it was evident that the levels of expression of decorin mRNA in MG-63 or UACC-903 cells were $\sim 10$ - and 50-fold lower than those of skin fibroblasts, respectively. Moreover, SV40-transformed skin fibroblasts (LNSV cells) lost their ability to synthesize decorin (Fig. $1 \mathrm{~A}$, lane 5). Additional Northern blotting using total RNA from colon carcinoma cells (WiDr/HT-29 and HCT116), squamous cell carcinoma (A431), and two additional hematopoietic cell lines (CHRF, and HEL92.1.7) showed no decorin-specific transcripts even after prolonged exposure of the autoradiograms (not shown). Immunoblotting of media conditioned by the various cell lines showed no detectable proteoglycan in all the transformed cell lines with the exception of diploid fibroblasts (Fig. $1 \mathrm{~B}$, lanes 6 and 9). Although decorin mRNA was detected in osteosarcoma MG-63 and melanoma UACC-903 cells, only trace amounts of secreted proteoglycan could be detected in MG-63 but not in UACC-903 cells using a very sensitive procedure such as chemiluminescence and Western blotting. Collectively, these results indicate that decorin is not constitutively synthesized by all the transformed cell lines tested, 15 in total, and suggest that decorin is not required for growth in culture of these malignant cells.

Ectopic expression of decorin proteoglycan or core protein induces growth suppression in a variety of transformed cells. To investigate whether de novo expression of decorin in cells that otherwise do not constitutively express this gene caused any change in growth rate, we generated stably-transfectant clones from five cell lines including human Saos-2 osteosarcoma, HeLa epidermoid carcinoma, HT-1080 fibrosarcoma, HL-60 promyelocytic leukemia cells, and murine M2 melanoma cells. We used two human constructs encoding either the
A
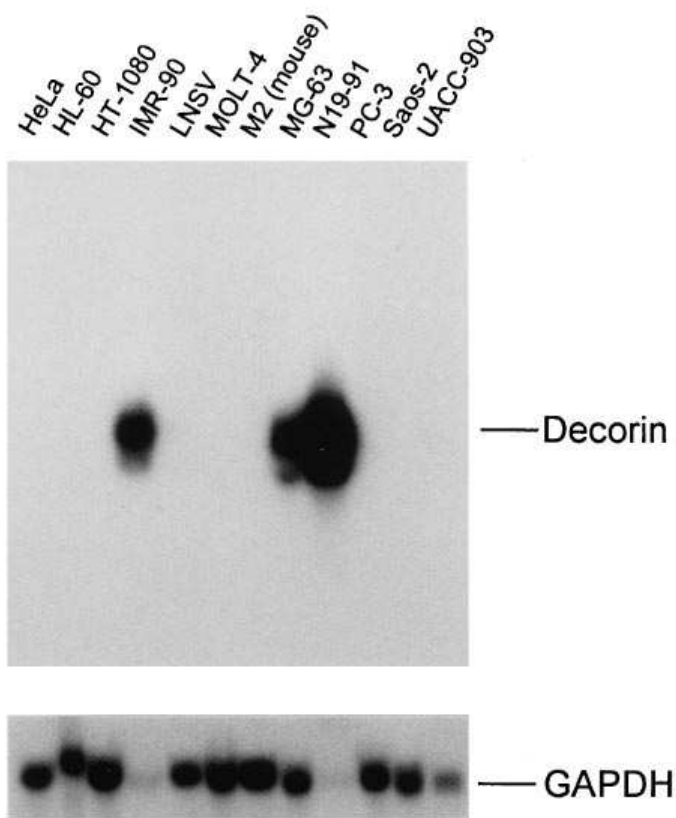

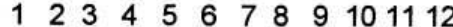
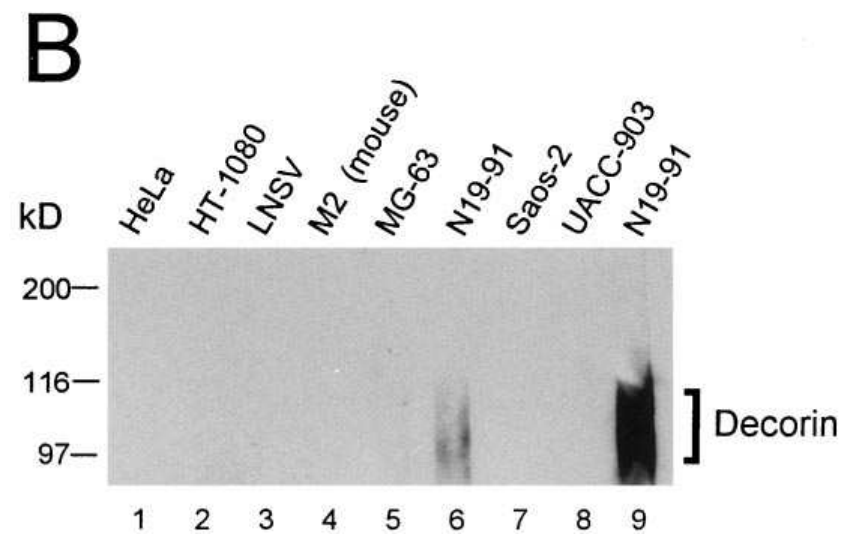

Figure 1. Lack of constitutive decorin expression in established cancer cell lines and virally-transformed fibroblasts. $(A)$ is a survey by Northern blotting of total RNA from various cell lines as indicated at the top, hybridized with either human decorin or GAPDH. $20 \mu \mathrm{g}$ of total RNA were used from all cell lines with exception of lung (lane 4 ) and skin (lane 9 ) fibroblasts where only $5 \mu \mathrm{g}$ were used. For the definition of the various cell lines, see Methods. (B) An immunoblotting analysis of media conditioned for $24 \mathrm{~h}$ by various cell lines as indicated on the top using an antidecorin antibody and chemiluminescence. The migration of decorin is marked on the right, while the migration of protein standard in $\mathrm{kD}$ is marked on the left.

full-length decorin proteoglycan (13) or a mutated decorin ( $\Delta$ decorin) insert (16) both cloned into the pcDNA3 vector driven by the potent CMV promoter. In the latter case, $\mathrm{Ser}^{7}$, the site of attachment for the only glycosaminoglycan chain (16), was substituted with an alanine residue thereby resulting in the secretion of the protein core containing the N-linked oligosaccharides but lacking the glycosaminoglycan side chain. A number of clones expressing various levels of the two tran- 
A

Saos-2 Decorin
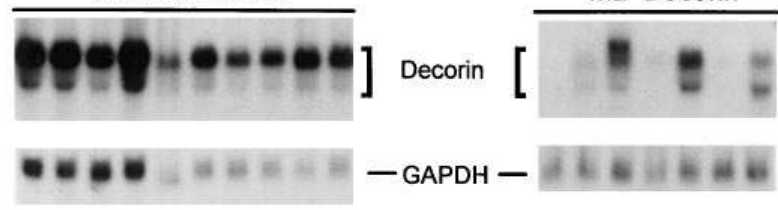

Saos-2 $\Delta$ Decorin

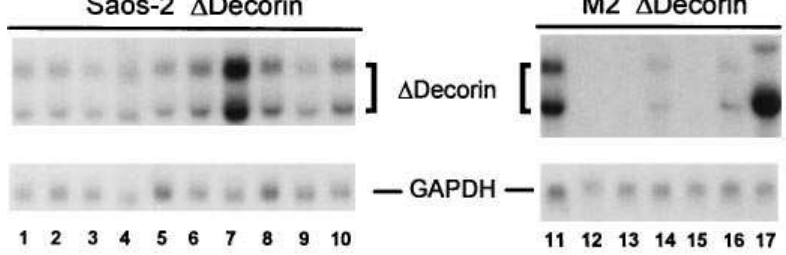

B

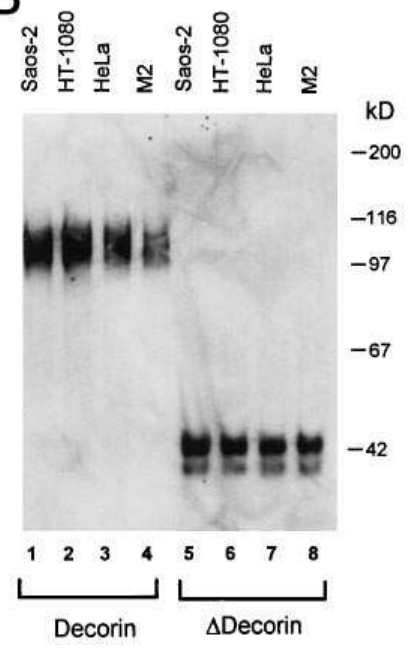

Figure 2. Expression of decorin in various stably-transfected tumor cell lines. $(A)$ Representative Northern blotting analyses of total RNA extracted from G418-resistant clones stably transfected with either decorin or $\Delta$ decorin as indicated on the top. The full-length decorin vector cloned into pcDNA3 results in two transcripts of $\sim 1.6$ and $\sim 1.9 \mathrm{~kb}$, respectively, because of two polyadenylation signals (13). The $\Delta$ decorin contains an additional $200 \mathrm{bp}$ of $3^{\prime}$ untranslated region and thus resulted in two transcripts of $\sim 1.6$ and $\sim 2.1 \mathrm{~kb}$, respectively (16). The values are normalized on GAPDH. (B) Representative Western blotting analyses of media conditioned for $24 \mathrm{~h}$ by the various cell lines as indicated on the top, and probed

with an antidecorin antibody directed against the amino terminal peptide. Notice that the cells transfected with decorin or $\Delta$ decorin show the predicted proteoglycan or protein core of $\sim 100$ or $42 \mathrm{kD}$, respectively.

scripts of decorin or $\Delta$ decorin were observed (Fig. $2 A$ ), with the greatest transfection efficiency in Saos-2 cells. Immunoblotting analyses using antidecorin antibodies and media conditioned for $24 \mathrm{~h}$ by various stably-transfected clones expressing either decorin or $\Delta$ decorin showed the expected fully-glycosylated proteoglycan or protein core running as $\sim 100$ or $42 \mathrm{kD}$, respectively (Fig. $2 \mathrm{~B}$ ). These experiments were repeated several times with similar results. When the growth kinetics of representative decorin-expressing clones were assessed, it was evident that the synthesis of decorin or $\Delta$ decorin was sufficient to retard the growth of all the tumor cell lines (Fig. 3), with the most profound inhibition occurring in the osteosarcoma Saos-2 cells (Fig. $3 A$ ). A marked repression of cell growth comparable to the HT-1080 cells, was also obtained with the HL-60 promyelocytic cells (not shown). As a further negative control for nonspecific effects on cell proliferation, we used stable transfection of domain III of human perlecan (2) driven by the same CMV promoter and found no appreciable changes in the growth of HT-1080 cells (not shown).

The similarity of the effects between the cells synthesizing the protein core alone and those synthesizing the fully-glycosylated proteoglycan indicated that the growth-suppressing properties of decorin did not depend on the GAG chains. Furthermore, because the HL-60 cells harbor a homozygous deletion of p53 (20) while the Saos-2 osteosarcoma are essentially defective in retinoblastoma gene (21), our results indicate that these two important regulators of the cell cycle are not required for the effects of decorin on tumor cell growth.

Exogenous decorin inhibits the growth of various transformed cell lines. Next, we asked whether exogenous decorin could also inhibit the growth of various transformed cell lines. To this end, we purified human recombinant decorin from media conditioned by Chinese hamster ovary cells stably transfected with a decorin expressing vector (6). The final product derived from C4-hydrophobic chromatography was checked for purity by SDS-PAGE and Western immunoblotting with a polyclonal antibody specific for the decorin protein core (17).

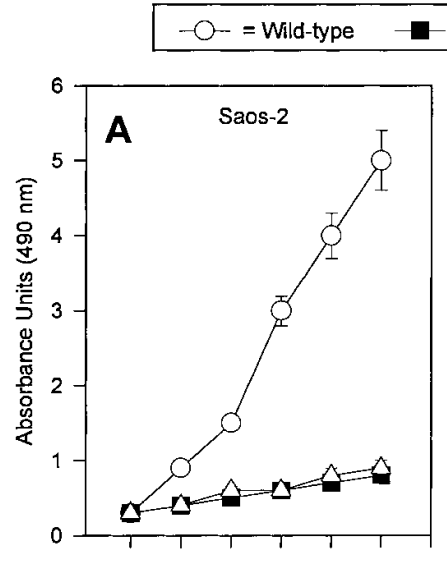

$=$ Decorin $\triangle=\Delta$ Decorin
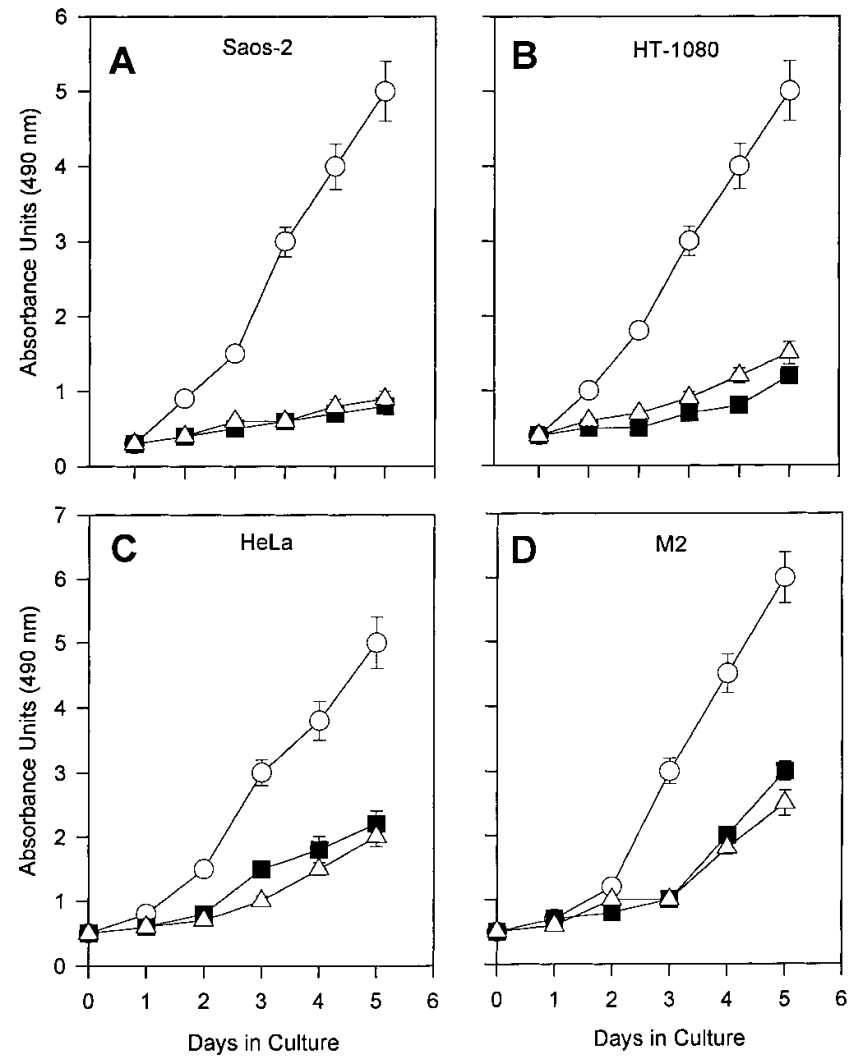

Figure 3. Ectopic expression of decorin or its protein core induces growth suppression in various tumor cell lines. The number of proliferating cells was established using a nonradioactive tetrazolium/formazan assay (42) using wild-type cells $(\bigcirc)$, or cells synthesizing either the fully glycosylated decorin (ם), or $\Delta$ decorin lacking the glycosaminoglycan side chain $(\triangle)$. The values are the mean \pm SD of three independent experiments $(n=5 /$ time point $)$. 
A
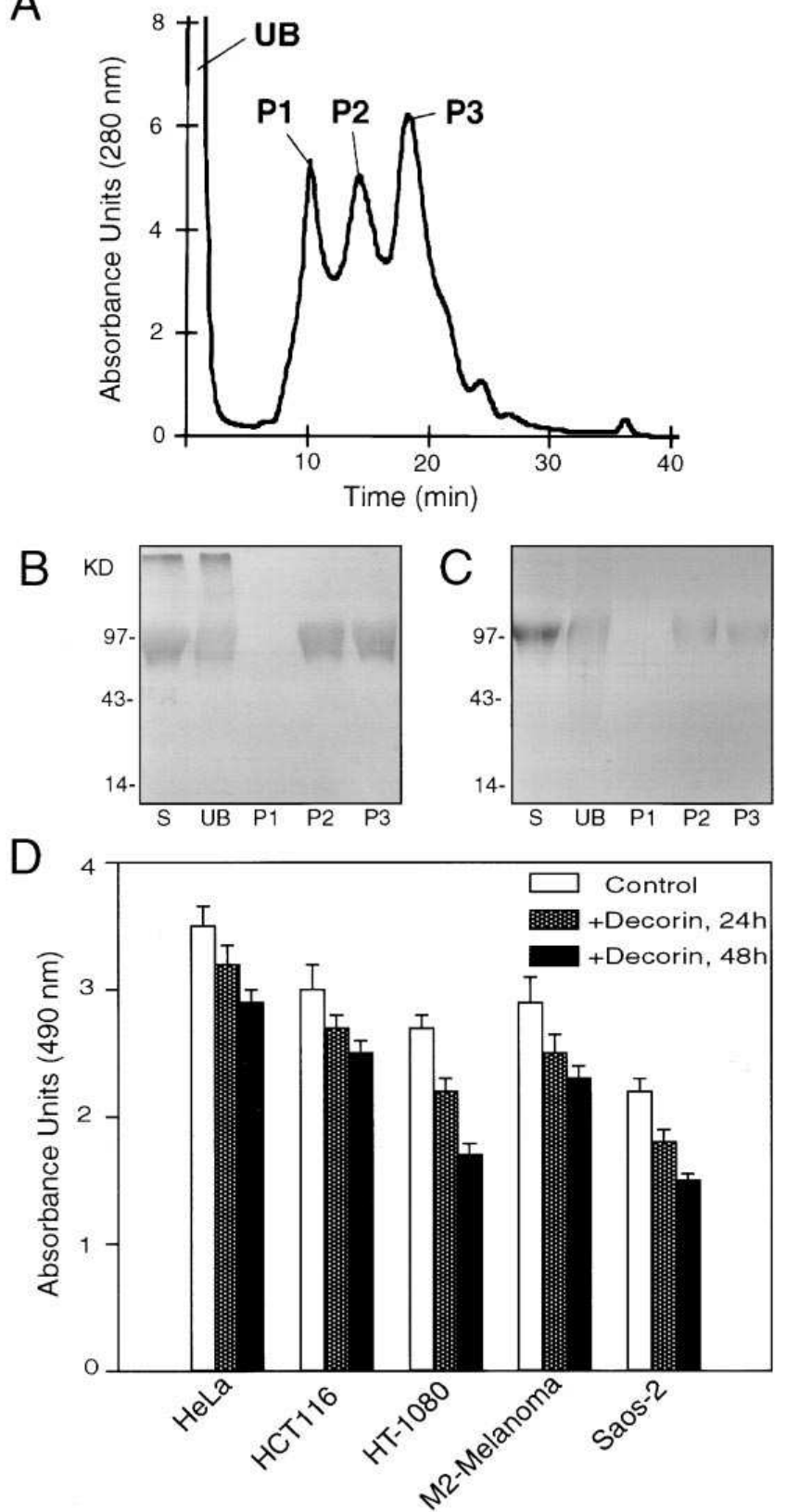

Figure 4. Addition of human recombinant decorin suppresses the growth of various tumor cell lines. Purification of human recombinant decorin from the secretion of Chinese hamster ovary cells stably transfected with a decorin expressing vector. $(A)$ A typical chromatogram from a C4-hydrophobic column of DEAE-purified decorin. $U B$, unbound material; $P 1-P 3$, eluted peaks $1-3$, respectively. (B) Double-stained Coumassie/Toluidine blue SDS-PAGE of the fractions derived from the chromatogram in $A$ to reveal protein and proteoglycan, respectively. $S$, starting material. The migration of molecular weight markers, in $\mathrm{KD}$, is indicated in the left margin. $(C)$ Western immunoblotting analysis of the same material as in $B$ using a polyclonal antibody directed against the amino terminal end of human decorin. Note that there are no detectable contaminants in the final purified decorin peaks and that the decorin in the two peaks (P2 and P3) likely differ in their degree of aggregation. $D$ shows a representative cell proliferation assay (mean $\pm \mathrm{SD}, n=5$ ) of cells incubated with either DME alone (Control) or with $100 \mu \mathrm{g} / \mathrm{ml}$ decorin (pooled P2 and $\mathrm{P} 3$ peaks) for 24 or $48 \mathrm{~h}$, as indicated.
Because of the nondenaturing conditions and the lack of chaotropic agents during the purification steps, all the purified recombinant decorin was virtually native, similar to that synthesized endogenously by the stably transfected clones. This highly purified human recombinant decorin, essentially free of contaminating proteins (Fig. 4, $A-C$ ), was tested for biological activity. In all cases, there was a time-dependent inhibition of growth (Fig. $4 \mathrm{D}$ ), thus corroborating the effects found in the stably expressing clones detailed above.

De novo expression of decorin is associated with marked induction of p21, its nuclear translocation, and a concomitant increase in cells arrested in $G_{1}$. Northern blot analysis of steady state mRNA levels encoding p21, an inhibitor of cyclin-dependent kinase activity $(22,23)$, showed a marked upregulation of this gene in both the decorin and $\Delta$ decorin-synthesizing tumor cell lines, regardless of their histogenetic origin (Fig. $5 A$ ). Normalization on either rRNA or GAPDH gave similar results with a 4-10-fold increase in p21 mRNA in all the cell lines. Western blotting using a monoclonal antibody directed against the p21 protein showed also upregulation of this gene (Fig. 5 B). In contrast, the endogenous protein levels of p27, another important CDK inhibitor and mediator of extracellular antimitogenic signals (24), remained essentially unchanged in all the transfected cells as determined by using an antibody specific for human p27 (not shown).

The changes in p21 mRNA and protein levels were corroborated by the marked augmentation and concentration of p21 immunoreactive protein in the nuclei of cells expressing either decorin or $\Delta$ decorin (Fig. 6). In agreement with these data,

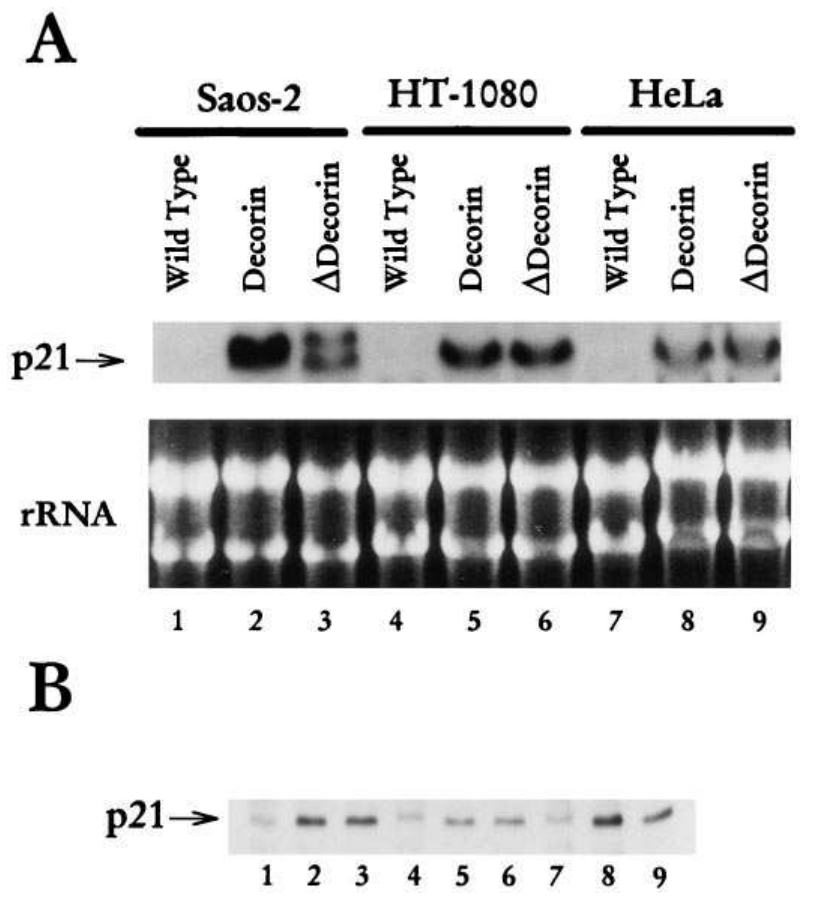

Figure 5. Induction of p21 in decorin-synthesizing tumor cell lines. Northern blotting analysis $(A)$ of total RNA from mock-transfected tumor cells or cells expressing decorin or $\Delta$ decorin as indicated on the top. Notice the marked induction of the p21 transcript. (B) Western blotting analysis of equal amounts of cell lysates (same as in $A$ ) probed with the $6 \mathrm{~B} 6$ monoclonal antibody directed against the human $\mathrm{p} 21$ protein. 

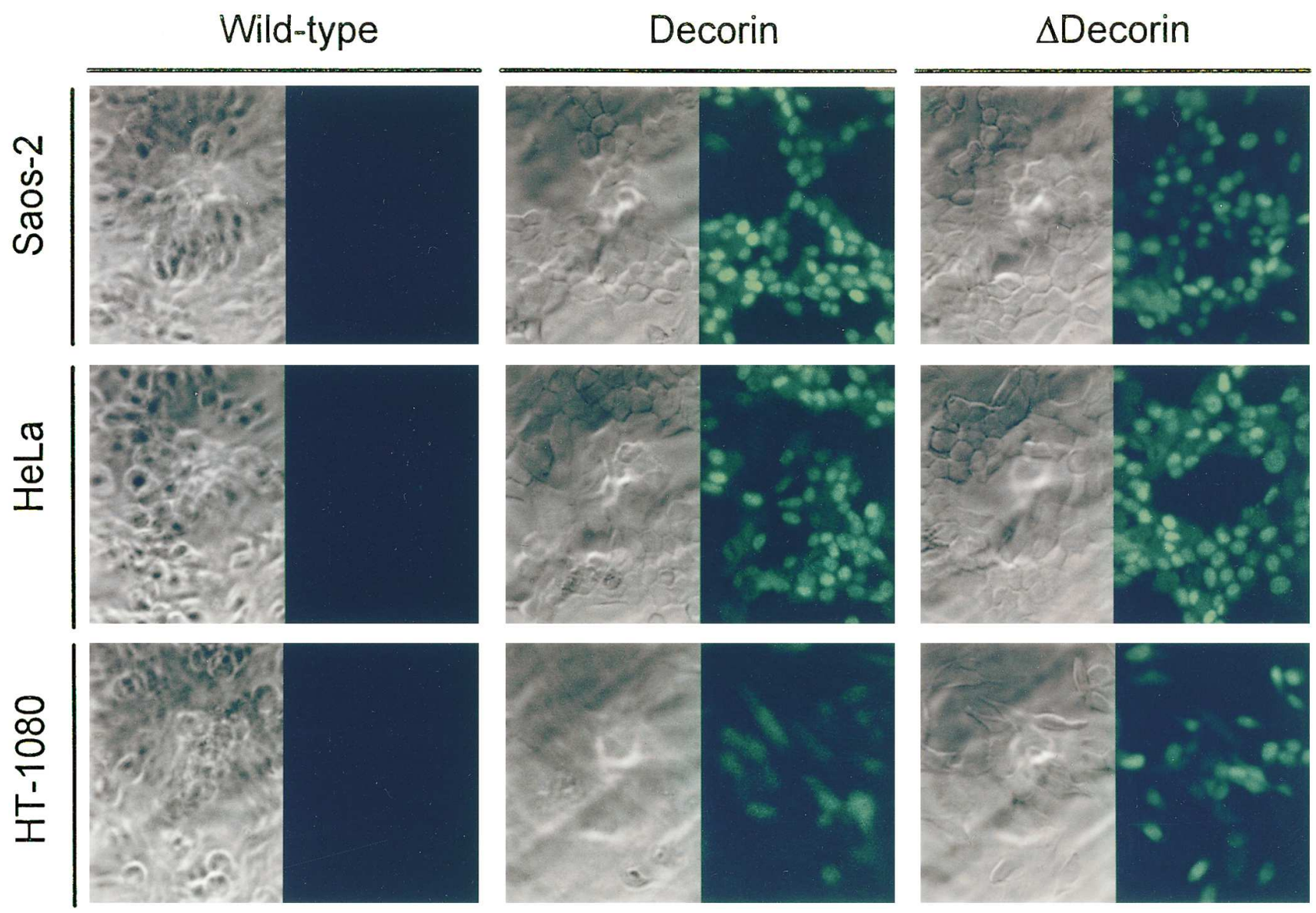

Figure 6. Induction of nuclear p21 in cells stably transfected with either decorin or $\Delta$ decorin cDNA. The genotype of the cells (i.e., wild-type cells, or cells transfected with the either decorin- or $\Delta$ decorin-containing vector), is indicated in the top margin. The cell type is indicated in the left margin. The left and right sides in each panel represent transmission and fluorescence microscopy of the same field, respectively. Notice the presence of immunoreactive p21 protein in all the nuclei of the decorin- and $\Delta$ decorin-expressing cells. Indirect immunofluorescence analysis was performed essentially as described before (14) using the 6B6 mouse monoclonal antibody against the human p21 protein and confocal laser microscopy. Representative fields of cultured cells are shown at the same magnification $(\times 60)$.

FACS $^{\circledR}$ analyses revealed a significant increase in the proportion of cells arrested in the $\mathrm{G}_{1}$ phase of the cell cycle (Fig. 7). Hence, the growth-suppressing function of decorin results from its ability to specifically induce endogenous $\mathrm{p} 21$ expression.

Requirement of 21 for the decorin-induced growth suppression. In the next series of experiments, we sought to determine if expression of p21 gene was a sine qua non for the growth suppressive properties of decorin. To address this question, we generated permanently-transfected decorinexpressing HCT116 cells: a human colon carcinoma cell line harboring a homozygous disruption of the p21 gene (15). As a positive control, we transfected decorin into the isogenic parental cells with a p21+/+ genotype. The HCT116 are nearly diploid cells that harbor p53 wild-type alleles and a full-length retinoblastoma protein, but are deficient in mismatch repair $(15,25,26)$. As predicted from the results described above, ectopic expression of decorin by the parental cells with a p21+/+ genotype resulted in a marked inhibition of cellular growth (Fig. $8 \mathrm{~A}$ ) and concurrent upregulation of p21 mRNA levels (not shown). In contrast, decorin was totally ineffective in the tumor cells with a p21-/- genotype (Fig. 8 B). FACS ${ }^{\circledR}$ analyses revealed a significant increase of the fraction of the cells in the $\mathrm{G}_{1}$ phase of the cell cycle in three independent experiments (Fig. 9, $A-C$ ), as well as a prominent increase of immunoreactive p21 protein (Fig. $9 \mathrm{D}$ ). These data provide definitive and unequivocal evidence for the requirement of p21 induction to achieve decorin-mediated growth arrest, and demonstrate that $\mathrm{p} 21$ is necessary for the downstream effects of decorin on the cell cycle machinery.

\section{Discussion}

Understanding the mechanisms that lead to the invasion of host tissues by a growing population of neoplastic cells is a major task of cancer research. Recent advances in the biochemistry and biology of tumor extracellular matrix has steered the focus on new conceptual issues regarding the role of matrix proteins in regulating cancer growth (27). It is becoming evident that to fully understand the mechanisms that guide the tumor cells to invade host tissues, the complex interactions between matrix proteins and tumor cells need to be explored in detail. The results of this investigation provide insights into the potential mechanism of action of decorin, a proteoglycan implicated previously in the control of cell proliferation $(13,28)$. 


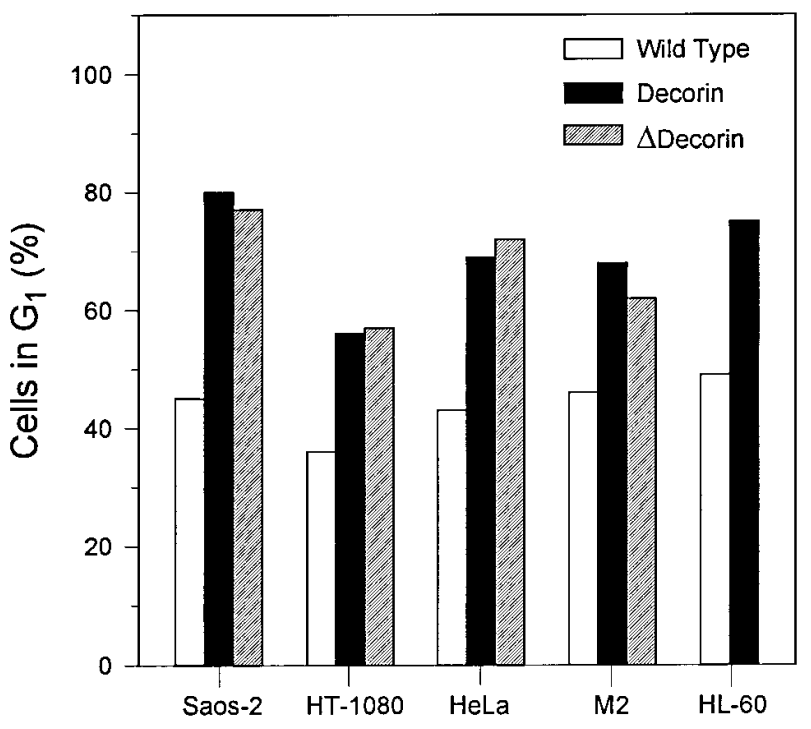

Figure 7. Proportion of cells in the $\mathrm{G}_{1}$ phase of the cell cycle as determined by FACS ${ }^{\circledR}$ analysis. The cell type is indicated in the bottom margin. The data represent the mean of three independent experiments run in duplicate with $\mathrm{SD}<15 \%$ of the mean.

The principal finding of this study is that de novo expression of decorin, either as a fully glycosylated proteoglycan or as a protein core, in a variety of tumorigenic cell lines correlates with a reduction in growth rates and induction of $\mathrm{p} 21$, a protein that controls the $\mathrm{G}_{1}-\mathrm{S}$ transition and is a dual inhibitor of CDKs $(22,23)$ and proliferating cell nuclear antigen (29). In addition, when the same wild-type cells were cultured in the presence of exogenous recombinant decorin, there was an appreciable inhibition of growth. These data are corroborated by an independent study demonstrating that transfection of decorin, but not of biglycan or fibromodulin, into NIH-3T3 driven by a CMV promoter, as in this study, induces growth suppression (V.-M. Kähäri, personal communication).

The biological response to decorin appears specific for $\mathrm{p} 21$, insofar as p27 was not affected by decorin. This is interesting in light of the fact that fibrillar collagen, a molecule that closely interacts with decorin in vitro (30) and in vivo (3), inhibits smooth muscle cell proliferation by inducing p27 levels and, to a lesser extent, p21 levels (31). In addition to promoting cellular adhesion and cytoskeletal organization, extracellular matrix proteins such as type I collagen may also subvert oncoprotein signaling pathways typical of the malignant phenotype (32).

The decorin-induced p21 upregulation leads to translocation of the protein into the nuclei of transfected cells where the p21-induced inhibitory effects on the cell cycle machinery presumably would take place, thereby suppressing the malignant properties of the cells. Indeed, three of the stably transfected cell lines, Saos-2, HT-1080 and HeLa cells, did not form tumors in mice even in the presence of Matrigel, a tumor-inducing extracellular matrix extracted from the EHS tumor (our unpublished results). In contrast, all the wild-type counterparts formed visible tumors within 7-10 d after subcutaneous inoculation.

Our previous studies have shown that colon carcinoma WiDr/HT29 cells, when transfected with a decorin-expressing

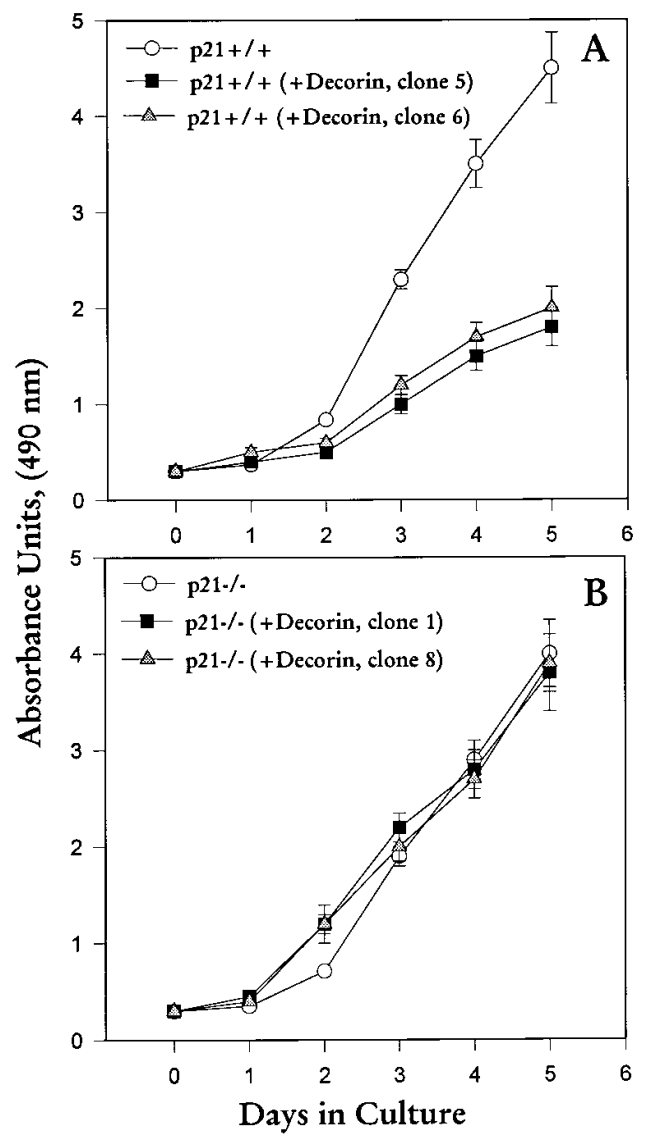

Figure 8. Ectopic expression of decorin fails to induce growth suppression in human colon carcinoma cells HCT116 harboring a homozygous disruption of the $\mathrm{p} 21$ gene. The values represent the mean \pm SD of two independent experiments each run in quadruplicate. The genotype of the cells is indicated.

vector, become growth arrested in $\mathrm{G}_{1}$ via a TGF- $\beta$-independent pathway, do not form tumors in scid/scid mice and reversibly induce p21 $(13,14)$. The present results eliminate the possibility that this is a cell type-specific phenomenon resulting from some genetic alterations in the WiDr/HT29 cells and establish a generality for the decorin-induced growth suppression. Moreover, we provide definitive evidence that the endogenous $\mathrm{p} 21$ is required for these effects to take place, since HCT116 colon carcinoma cells deficient in the p21 gene (15) fail to respond to decorin. In contrast, the isogenic parental cells with a p21+/+ genotype became growth-arrested in $\mathrm{G}_{1}$ with a concurrent induction of the endogenous p21 gene.

In the nuclei of normal diploid cells, p21 exists as a quaternary structure complexed with a cyclin, a CDK, and PCNA $(33,34)$ where it functions as a titratable buffer, that is, p21 can set the cyclin threshold necessary for cell cycle progression (35). Assuming that two and not more than two molecules of p21 are required for proper CDK inhibition, then a twofold induction of p21 would be sufficient to block cell cycle progression. In our experiments, the steady state levels of both p21 mRNA and protein were elevated several-fold in all the decorin-expressing cells which should have prompted inhibition of CDK activity and $\mathrm{G}_{1}$ arrest, as in the case of colon carcinoma cells (14). We further show that the protein core alone is capa- 

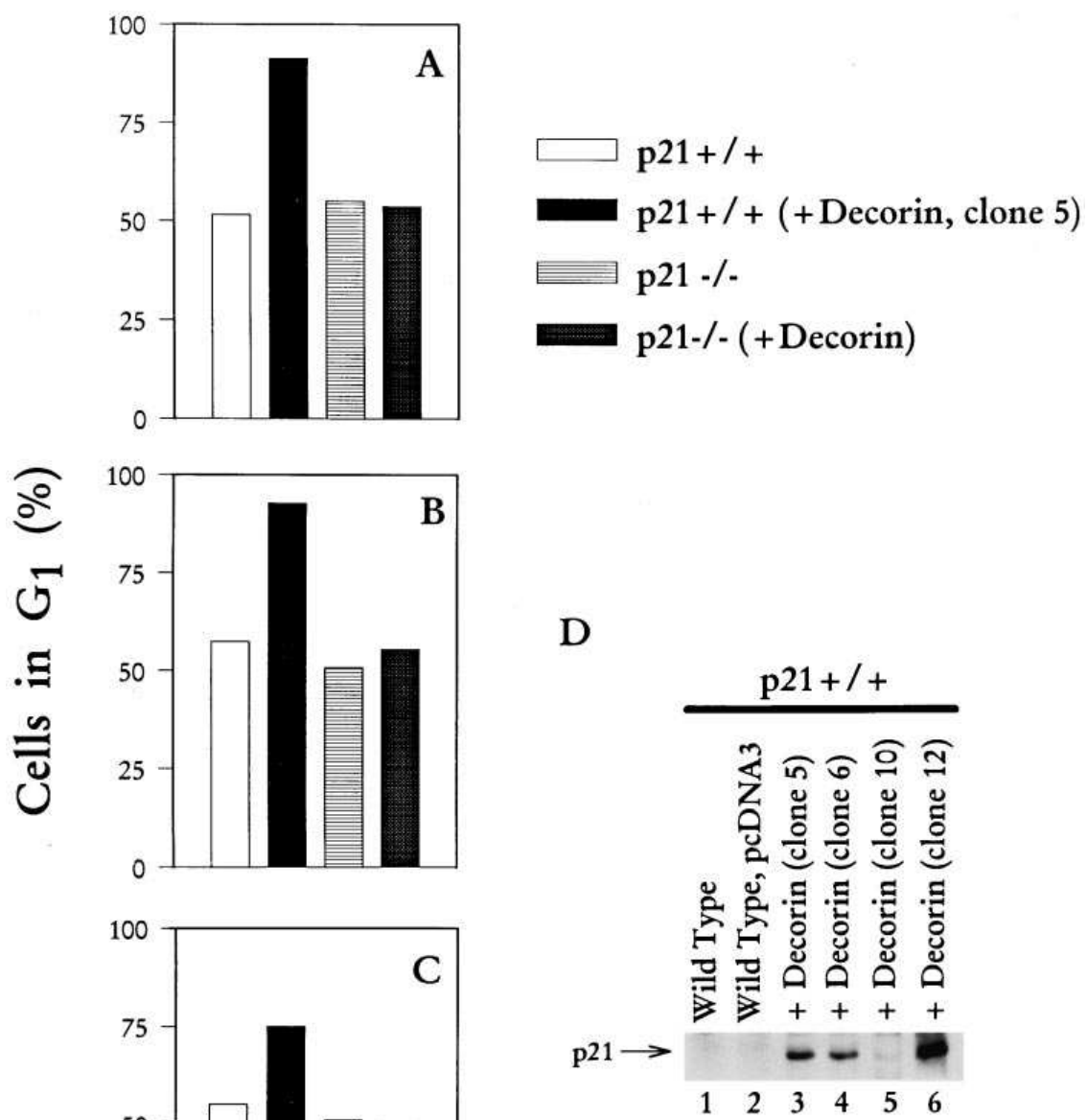

Figure 9. FACS ${ }^{\circledR}$ analysis $(A-C)$ and Western immunoblotting $(D)$ of HCT116 harboring a wild-type p21 or a disrupted p21 gene after transfection with decorin. The bar graph depicts the percentage of cells in the $\mathrm{G}_{1}$ phase of the cell cycle as indicated in top right margin. The data represent the mean of duplicate determinations from three independent experiments. $(D)$ Immunoblotting analysis using the 6B6 mouse monoclonal antibody against the human $\mathrm{p} 21$ protein. The various cells are as indicated in the top right margin.

ble of mediating all the growth suppression insofar as a mutated form of decorin lacking the GAG chain was capable of inducing similar responses in all the cells tested. These data suggest that the arch-shaped decorin (36) would contain all the information for inducing these biological effects in various cells. Predictably, the central domain encompassing the 10 tandem leucine-rich repeats, is likely responsible for cell-surface binding. This region has been proposed as the collagen-binding domain of decorin and its inner concave face of the decorin molecule would allow ample interaction with a ligand cell surface protein/receptor (36).

The similarity of the response to decorin in the several human cell lines and the induction across species suggest that there is a general, well-conserved signal-transducing pathway that is operational in mammalian cells. Our results predict that interaction between decorin and a specific surface receptor would trigger a signal cascade that culminates with the induction of CDK inhibitors, and that decorin would be directly involved in controlling the endogenous levels of at least one negative modulator of cell cycle checkpoints. We have recently discovered that in A431 squamous carcinoma cells decorin ac- tivates the mitogen-activated protein kinase signal pathway which leads to a protracted induction of endogenous p21 and ultimately to cell cycle arrest (Moscatello, D.K., M. Santra, D.M. Mann, D. McQuillan, A.J. Wong, and R.V. Iozzo. Manuscript submitted for publication).

The ability of decorin to induce p21 gives further credence to the concept that increased production of proteoglycans around the malignant cells represents a specific biological response of the host designed to counterbalance, and perhaps, neutralize the invading tumor cells. The fact that the decorininduced growth suppression does not require functional p53 or retinoblastoma proteins further suggests that decorin may modulate p21 levels and growth via alternate pathway(s). This possibility is supported by the observations in cells harboring deletions or mutations of the p53 gene (37-41). It is possible that p53-independent pathways of p21 induction may rescue p53-deleted or p53-mutated tumor cells from aberrant proliferation resulting from lack of p21 induction. Such considerations highlight the importance of uncovering negative modulators of the cell-cycle machinery and illustrate a key role of extracellular matrix proteins in modulating tumor growth. 


\section{Acknowledgments}

We thank T. Waldman and B. Vogelstein for generously providing the HCT116 p21+/+ and p21-/- cells, V.-M. Kähäri for kindly sharing unpublished results, E. Ruoslahti for precious immunological reagents, and I. Eichstetter for excellent technical assistance.

This work was supported by National Institutes of Health grants RO1 CA39481, RO1 CA47282, RO1 CA46782, and R29 AR42320.

\section{References}

1. Iozzo, R.V. 1997. The family of the small leucine-rich proteoglycans: key regulators of matrix assembly and cellular growth. Crit. Rev. Biochem. Mol. Biol. 32:141-174.

2. Iozzo, R.V., and A.D. Murdoch. 1996. Proteoglycans of the extracellular environment: clues from the gene and protein side offer novel perspectives in molecular diversity and function. FASEB (Fed. Am. Soc. Exp. Biol.) J. 10:598614.

3. Danielson, K.G., H. Baribault, D.F. Holmes, H. Graham, K.E. Kadler, and R.V. Iozzo. 1997. Targeted disruption of decorin leads to abnormal collagen fibril morphology and skin fragility. J. Cell Biol. 136:729-743.

4. Border, W.A., N.A. Noble, T. Yamamoto, J.R. Harper, Y. Yamaguchi, M.D. Pierschbacher, and E. Ruoslahti. 1992. Natural inhibitor of transforming growth factor- $\beta$ protects against scarring in experimental kidney disease. $\mathrm{Na}$ ture (Lond.). 360:361-364.

5. Isaka, Y., D.K. Brees, K. Ikegaya, Y. Kaneda, E. Imai, N.A. Noble, and W.A. Border. 1996. Gene therapy by skeletal muscle expression of decorin prevents fibrotic disease in rat kidney. Nat. Med. 2:418-423.

6. Yamaguchi, Y., and E. Ruoslahti. 1988. Expression of human proteoglycan in Chinese hamster ovary cells inhibits cell proliferation. Nature (Lond.). 336:244-246.

7. Yamaguchi, Y., D.M. Mann, and E. Ruoslahti. 1990. Negative regulation of transforming growth factor- $\beta$ by the proteoglycan decorin. Nature (Lond.). 346:281-284.

8. Coppock, D.L., C. Kopman, S. Scandalis, and S. Gilleran. 1993. Preferential gene expression in quiescent human lung fibroblasts. Cell Growth Differ. 4: 483-493.

9. Mauviel, A., M. Santra, Y.Q. Chen, J. Uitto, and R.V. Iozzo. 1995. Transcriptional regulation of decorin gene expression. Induction by quiescence and repression by tumor necrosis factor- $\alpha$. J. Biol. Chem. 270:11692-11700.

10. Iozzo, R.V., and I. Cohen. 1993. Altered proteoglycan gene expression and the tumor stroma. Experientia (Basel). 49:447-455.

11. Adany, R., R. Heimer, B. Caterson, J.M. Sorrell, and R.V. Iozzo. 1990. Altered expression of chondroitin sulfate proteoglycan in the stroma of human colon carcinoma. Hypomethylation of PG-40 gene correlates with increased PG-40 content and mRNA levels. J. Biol. Chem. 265:11389-11396.

12. Iozzo, R.V. 1985. Neoplastic modulation of extracellular matrix. Colon carcinoma cells release polypeptides that alter proteoglycan metabolism in colon fibroblasts. J. Biol. Chem. 260:7464-7473.

13. Santra, M., T. Skorski, B. Calabretta, E.C. Lattime, and R.V. Iozzo. 1995. De novo decorin gene expression suppresses the malignant phenotype in human colon cancer cells. Proc. Natl. Acad. Sci. USA. 92:7016-7020.

14. De Luca, A., M. Santra, A. Baldi, A. Giordano, and R.V. Iozzo. 1996. Decorin-induced growth suppression is associated with upregulation of $\mathrm{p} 21$, an inhibitor of cyclin-dependent kinases. J. Biol. Chem. 271:18961-18965.

15. Waldman, T., K.W. Kinzler, and B. Vogelstein. 1995. p21 is necessary for p53-mediated $\mathrm{G}_{1}$ arrest in human cancer cells. Cancer Res. 55:5187-5190.

16. Mann, D.M., Y. Yamaguchi, M.A. Bourdon, and E. Ruoslahti. 1990. Analysis of glycosaminoglycan substitution in decorin by site-directed mutagenesis. J. Biol. Chem. 265:5317-5323.

17. Krusius, T., and E. Ruoslahti. 1986. Primary structure of an extracellular matrix proteoglycan core protein deduced from cloned cDNA. Proc. Natl. Acad. Sci. USA. 83:7683-7687.

18. El-Deiry, W.S., J.W. Harper, P.M. O’Connor, V.E. Velculescu, C.E. Canman, J. Jackman, J.A. Pietenpol, M. Burrell, D.E. Hill, Y. Wang, et al. 1994. WAF1/CIP1 is induced in p53-mediated $\mathrm{G}_{1}$ arrest and apoptosis. Cancer Res. 54:1169-1174.
19. Scholzen, T., M. Solursh, S. Suzuki, R. Reiter, J.L. Morgan, A.M. Buchberg, L.D. Siracusa, and R.V. Iozzo. 1994. The murine decorin. Complete cDNA cloning, genomic organization, chromosomal assignment and expression during organogenesis and tissue differentiation. J. Biol. Chem. 269:2827028281.

20. Danova, M., M. Giordano, G. Mazzini, and A. Riccardi. 1990. Expression of p53 protein during the cell cycle measured by flow cytometry in human leukemia. Leuk. Res. 14:417-422.

21. Shew, J.-Y., N. Ling, Z. Yang, O. Fodstad, and W.-H. Lee. 1989. Antibodies detecting abnormalities of the retinoblastoma susceptibility gene product $\left(\mathrm{pp} 110^{\mathrm{RB}}\right)$ in osteosarcomas and synovial sarcomas. Oncogene Res. 4:205214

22. Harper, J.W., G.R. Adami, N. Wei, K. Keyomarsi, and S.J. Elledge. 1993. The p21 Cdk-interacting protein Cip1 is a potent inhibitor of G1 cyclindependent kinases. Cell. 75:805-816.

23. El-Deiry, W.S., T. Tokino, V.E. Velculescu, D.B. Levy, R. Parsons, J.M. Trent, D. Lin, W.E. Mercer, K.W. Kinzler, and B. Vogelstein. 1993. WAF1, a potential mediator of p53 tumor suppression. Cell. 75:817-825.

24. Poliak, K., M. Lee, H. Erdjument-Bromage, A. Koff, J.M. Roberts, P. Tempst, and J. Massagué. 1994. Cloning of P27 ${ }^{\text {Kipl }}$, a cyclin-dependent kinase inhibitor and a potential mediator of extracellular antimitogenic signals. Cell. 78:59-66.

25. Waldman, T., C. Lengauer, K.W. Kinzler, and B. Vogelstein. 1996. Uncoupling of $\mathrm{S}$ phase and mitosis induced by anticancer agents in cells lacking p21. Nature (Lond.). 381:713-716.

26. Polyak, K., T. Waldman, T.-C. He, K.W. Kinzler, and B. Vogelstein. 1996. Genetic determinants of p53-induced apoptosis and growth arrest. Genes Dev. 10:1945-1952.

27. Iozzo, R.V. 1995. Tumor stroma as a regulator of neoplastic behavior. Lab. Invest. 73:157-160.

28. Ruoslahti, E., and Y. Yamaguchi. 1991. Proteoglycans as modulators of growth factor activities. Cell. 64:867-869.

29. Waga, S., G.J. Hannon, D. Beach, and B. Stillman. 1994. The p21 inhibitor of cyclin-dependent kinases controls DNA replication by interaction with PCNA. Nature (Lond.). 369:574-578.

30. Vogel, K.G., and J.A. Trotter. 1987. The effects of proteoglycans on the morphology of collagen fibrils formed in vitro. Collagen Relat. Res. 7:105-114.

31. Koyama, H., E.W. Raines, K.E. Bornfeldt, J.M. Roberts, and R. Ross. 1996. Fibrillar collagen inhibits arterial smooth muscle proliferation through regulation of Cdk2 inhibitors. Cell. 87:1069-1078.

32. Travers, H., N.S. French, and J.D. Norton. 1996. Suppression of tumorigenicity in Ras-transformed fibroblasts by $\alpha 2(\mathrm{I})$ collagen. Cell Growth Differ. 7: 1353-1360.

33. Morgan, D.D. 1995. Principles of CDK regulation. Nature (Lond.). 374: 131-134.

34. Pines, J. 1995. Cyclins, CDKs and cancer. Semin. Cancer Biol. 6:63-72.

35. Harper, J.W., S.J. Elledge, K. Keyomarsi, B. Dynlacht, L.-H. Tsai, P. Zhang, S. Dobrowolski, C. Bai, L. Connell-Crowley, E. Swindell, et al. 1995. Inhibition of cyclin-dependent kinases by p21. Mol. Biol. Cell. 6:387-400.

36. Weber, I.T., R.W. Harrison, and R.V. Iozzo. 1996. Model structure of decorin and implications for collagen fibrillogenesis. J. Biol. Chem. 271:3176731770 .

37. Steinman, R.A., B. Hoffman, A. Iro, C. Guillouf, D.A. Libermann, and M.E. El-Houseini. 1994. Introduction of $p 21$ (WAF-1/CIP1) during differentiation. Oncogene. 9:3389-3396.

38. Michieli, P., M. Chedid, D. Lin, J.H. Pierce, W.E. Mercer, and D. Givol. 1994. Induction of WAF1/CIP1 by a p53-independent pathway. Cancer Res. 54: 3391-3395.

39. Schwaller, J., H.P. Koeffler, G. Niklaus, P. Loetscher, S. Nagel, M.F. Fey, and A. Tobler. 1995. Posttranscriptional stabilization underlies p53-independent induction of $\mathrm{p} 21^{\mathrm{WAF} 1 / \mathrm{CIP} 1 / \mathrm{SDI} 1}$ in differentiating human leukemic cells. $J$. Clin. Invest. 95:973-979.

40. Zubiaur, M., L.W. Forman, L.L. Stice, and D.V. Faller. 1996. A role for activated $\mathrm{p} 21^{\text {ras }}$ in inhibition/regulation of platelet-derived growth factor (PDGF) type- $\beta$ receptor activation. Oncogene. 12:1213-1222.

41. Alpan, R.S., and A.B. Pardee. 1996. P21 $1^{\mathrm{WAF} 1 / \mathrm{CIP} 1 / \mathrm{SDI} 1}$ is elevated through a p53-independent pathway by mimosine. Cell Growth Differ. 7:893-901.

42. Buttke, T.M., J.A. McCubrey, and T.C. Owen. 1993. Use of an aqueous soluble tetrazolium/formazan assay to measure viability and proliferation of lymphokine-dependent cell lines. J. Immunol. Methods. 157:233-240. 